EDITORIAL

\title{
Informação e novas oportunidades
}

O Instituto Brasileiro de Informação e Ciência e Tecnologia (Ibict) vem diversificando e aprofundando seu campo de atuação nas linhas de prestação de serviços. As áreas cobertas pelo Programa Prossiga e pelo Projeto da Biblioteca Digital Brasileira(BDB) já representam efetiva sinergia com as necessidades da comunidade acadêmica e tecnológica brasileira.

Baseando-se nas transformações da sociedade, somadas as mudanças de paradigmas políticos, econômicos, científicos e tecnológicos, e na busca de novas condições de inserção dos países em desenvolvimento no mercado mundial, a atual diretoria do Ibict vem dando ênfase também a um novo projeto - Gestão estratégica da informação para a inovação (G-Inova), voltado especificamente para as micro, pequenas e médias empresas brasileiras.

O objetivo básico do G-Inova é o preenchimento de lacunas e gargalos tecnológicos relacionados principalmente às necessidades informacionais das empresas, com um foco especial na pauta de exportação. Diante desse panorama, e em face dos desafios impostos pela conjuntura, é imperativo que esse serviço seja uma cooperação entre o instituto e diversas organizações públicas e privadas, como o Ministério do Desenvolvimento, Indústria e Comércio Exterior (MDIC),Instituto de Tecnologia do Paraná ( Tecpar), Instituto de Pesquisa Tecnológica (IPT), Serviço Brasileiro de Apoio às Micro e Pequenas Empresas (Sebrae),Confederação Nacional da Indústria( CNI),Instituto Nacional de Propriedade Industrial ( Inpi), entre outras.

Assim, será ampliada a cobertura e o acesso às informações da área da tecnologia industrial básica (TIB) com ênfase nas patentes e seus diversos segmentos, como especialistas, recursos informacionais, informações setoriais, ofertas de serviços tecnológicos, normas técnicas para exportação, rotulagem ambiental, ciclo de vida do produto, entre outros.

O G-Inova será desenvolvido em ambiente WEB e vai operar como um portal de informação. Dessa forma, esperamos que a nova etapa do Instituto que estamos apresentando se transforme em um instrumento eficaz de geração de novas oportunidades e projetos cooperativos, para que melhor possamos servir o país.

Consciente das transformações da sociedade global e registrando, em seus artigos, os reflexos dessa turbulência, a revista Ciência da Informação coloca à disposição de seus leitores o primeiro número de 2002.

\author{
Dr. Eloi S. Garcia \\ Diretor do Ibict
}

